\title{
Reviews in brief
}

\begin{abstract}
Anatomie chirurgicale des racines hautes du plexus brachial et du nerf accessorius dans le creux sus-claviculaire. Application au traitement des avulsions radiculaires traumatiques du plexus brachial (The surgical anatomy of the upper roots of the brachial plexus and the accessory nerve in the supraclavivular fossa. The application to the treatment of traumatic avulsion of the roots of the plexus)

G Herzberg, A Bouchet, JP Carret, A Morin (1990) Soc Anat Paris 22.06 .90
\end{abstract}

A study was made on dissections of 20 fresh anatomical specimens of the upper roots of the brachial plexus $\mathrm{C} 5, \mathrm{C} 6, \mathrm{C} 7$ from their exits from the vertebral canal. A second study of 14 dissections was concerned with the connections of the accessory nerve in the supraclavicular fossa. The aim of the study was to facilitate the exposure by the anterolateral route of nerve stumps after traumatic avulsion of the brachial plexus. With complete avulsion the anatomical basis of anastomosis of the suprascapular nerve by the accessory nerve is described (Authors' summary).

Existe-t-il un ligament nuchal chez l'homme? (Is there a nuchal ligament in man?)

M Awzu Pereira da Silva (1990) Soc Anat Paris 22.06.90

Human anatomy with its macroscopic and microscopic techniques has been called upon to assist in research into the antropology of the support of the head in people subjected to intentional deformity of the head in the past in France. Elements in the neck region are involved in the concept. Apart from the spine and its constituents, skin, muscles, fascia, vessels and nerves, the nuchal ligament by its topographical localisation appears to play a role as a strut in maintaining symmetry during the movements of flexion and extension and lateral inclination of the head on the neck. The anatomical indentity of this ligament is, however, debated. Together with the first results of this study, an analysis of preceding studies on the subject is presented (Authors' summary).

Anatomie descriptive du sphincter uréthral chez l'embryon humain de $31 \mathrm{~mm}$ VC (Descriptive anatomy of the urethral sphincter in the $31 \mathrm{~mm}$ embryo)

D Bourdelat, JP Barbet, G Hidden (1990) Soc Anat Paris 22.06.90

With the aim of understanding the control of micturition in the embryo, a study was made of the muscles of the bladder and urethra in transverse cuts of a $31 \mathrm{~mm}$ human embryo in the Saints Pères collections. A distinction between the smooth and the striated muscle sphincters was already possible at this stage (Authors' summary)

L'arcade veineuse du nerf sciatique (The venous arcade of the sciatic nerve)

C Gillot (1990) Soc Anat Paris 22.06.90

This is derived from the axial vein, initially running in the embryo from the pelvic trunk, accompanying the exit of the sciatic nerve.

Its drainage in the lower limb is collected into the pre-axial vein, the future femoral vein. The plexus of the sciatic nerve persists as venules. In some cases a vein of 3-4 m diameter can be distinguished, the arcade of the sciatic nerve (ANS), which drains into the popliteal vein above, the deep femoral through perforating veins (P1, P2, P3), the medial circumflex vein $(\mathrm{CM})$ and terminates in the inferior gluteal vein (Gi) or ischial vein. Sometimes there is a larger $(4-6 \mathrm{~mm})$ arcade of the sciatic nerve. The vein of the sciatic nerve is a hypertrophied segment of this arcade. It arises from the subcondylar popliteal vein, passes posteriorly along the tibial nerve (NT) then the sciatic nerve (NS), on its anterior aspect. It terminates as a large vein by joining the deep femoral vein, passing through one of the three pedicle of the adductor magnus muscle. It can be the principal vein at the level of the thigh. It can be easily seen on anatomical sections and on MRI in a lateral position outside the adductor magnus (Authors' summary).

La voie infratemporal (The sutemporal route)

K Hentati, Ph Cornu, B Meyer, A Zouaoui, J Philippon, G Hidden (1990) Soc Anat Paris 25.05.90

The subtemporal approach is that which is preferred after a study begun a year previously on the surgical techniques for the treatment of neoplasms and vascular lesions at the base of the skull. This approach allows wide exposure of the middle fossa and can be extended to the orbit anteriorly and to the ptrygomaxillary fossa below (Authors' summary). 


\section{Reviews in brief (cont. page 192)}

Etude morphométrique des différents composants du pénis (A morphometric study of the different constituents of the penis) V Delmas, M Ch Dauge (1990) Soc Anat Paris 25.05.90

The penile functional variations. The aim of the present study was to compare from the morphometric point of view the flaccid and the erect penis (Authors summary).

Etude de la vascularisation de la phalange distale des doigts (A study of the vascularisation of the distal phalanges of the fingers) F Brunelli, F Nanfito (1990) Soc Anat Paris 25.05.90

The findings are reported of the dissection of 80 digits after injection of colored Latex. After dissection of the collateral arteries of the digit to the level of the first and the second phalanx, the study continued with the operating microscope to analyse the vascularisation of the pulp as well as that of the dorsal aspect of the distal phalanx. The particular features of the digital vascularisation of these 3 regions are reported (Authors' summary).

Biométrie de la vena cava inferior (segment sous-rénal) : dissection de 100 sujets frais (Measurements of the infrarenal part of the inferior vena cava in 100 fresh cadavers)

P Le Floch-Prigent (1989) Bull Assoc Anat $73: 19-24$

The infrarenal part of the inferior vena cava is a favored site for the insertion of antithrombosis devices. In 100 fresh adult cadavers the actual usable lengths and diameters of the vein at various levels were measured, together with those of the aorta, termination of the iliac veins and the origin of the iliac arteries at the same levels. The mean useful length of the inferior vena cava was $96 \mathrm{~mm}$ and the mean diameter was $17 \mathrm{~mm}$ at the mid point of the infrarenal part (Authors' summary).

Approche anatomo-radiologique de la pathologie mécanique de l'articulation péronéo-tibiale supérieure (Anatomico-radiologic approach to the pathological mechanisms affecting the superior tibiofibular articulation)

J-Y Lazennec, JM Feron, H Guérin-Surville, P Gauthier (1990) Bull Assoc Anat $74: 37-41$

The morphology and topography of the superior tibiofibular joint was studied in 150 dissections in the cadaver. The numerous anatomical and radiological variations explained the different pathologies seen in clinical practice. The authors emphasise the influence of this joint on ankle function and recommend the resection of the lower diaphysis when arthrodesis of the proximal tibiofibular joint is performed (Authors' summary).
L'anatomie de la musculature naso-labiale et du mésethmoide dans les fentes labio-maxillaires. Nouvelle approche chirurgicale de la chéiloplastie (The anatomy of the labionasal musculature and of the mesoethmoid in labiomaxillary clefts. A new approach to repair of hare lip)

D Anagnpostopoulous, $\mathrm{N}$ Liolios, $\mathrm{K}$ Kotsianos, $\mathrm{E}$ Miliaras, $\mathrm{P}$ Foroglou (1989) Bull Assoc Anat $73: 3-7$

An analysis of the role of the ectomesenchyme in facial organogenesis, and the biology of fetal and infant development of the head provide arguments for the application of new principles in the repair of hare lip and labiomaxillary clefts. Instead of skin repair alone, the procedure involves selective muscle reconstruction of the nasolabial borders, which are predominantly muscular. Cheilomesoethmoidoplasty is thus a valid procedure which has been used by the authors in 36 cases (Authors' summary).

Etude des sollicitations et quantification des pressions subies par la hanche en appui monopodal dans le plan sagittal (A study of the pressures sustained by the hip in the sagittal plane when bearing weight on one limb)

Th Quesnel, GP Gonon (1989) Bull Assoc Anat 73: 29-31

The pressure sustained by the hip in the coronal plane is well known, thanks to the work, of Pauwels, and has had some surgical applications. Pressure in the sagittal plane was considered by Pauwels to be negligible and has been little studied. In fact by using his methods and taking into account the moments from muscular action, it can be shown that the forces exerted in the sagittal plane are far from negligible and vary during the phases of weightbearing, from the body weight wher standing on the sole, to two and a half times the body weight when standing on the heel (Authors' summary).

Variation des pressions subies par la hanche durant la phase d'appui monopodal de la marche (Variation of pressure sustained by the hip during weightbearing on one leg when walking) Th Quesnel, G Sainte Rose, GP Gonon (1989) Bull Assoc Anat 73 : 33-36

Using the methodology of Pauwels, his study was complemented by measuring the pressures sustained by the hip not only in the coronal but also in the horizontal and sagittal planes during the phase of unilateral weightbearing when walking. The forces exerted on the hip are now well known, thanks to the work of Braune and Fischer, and are the result of the weight of the body, the muscular forces and the dynamic forces generated by walking. From our data the pressures sustained by the hip in each plane during the phases of unilateral weightbearing when walking (weightbearing on heel, sole and toes) have been quantified (Authors' summary). 


\section{Reviews in brief (cont. page 224)}

L'hépatectomie sous exclusion vasculaire totale. Principes anatomiques d'après 64 dissections (Hepatectomy under total vascular exclusion : anatomical principals derived from 64 dissections) JM Chevallier, E Delva, P Frileux, B Nordlinger, R Parc, C Huguet, L Hannoun (1990) Ann Chir $44: 444-451$

Intra-operative hemorrhage is the main surgical risk during liver resections. Nowadays hepatectomies for large or posterior liver tumors close to the hepatocaval junction can benefit from total hepatic vascular exclusion (HVE) involving portal triad exclusion and clamping of the inferior vena cava (IVC) below and above the liver. Anatomical aspects of HVE have been studied in 64 subjects by segmental occlusive phlebographies of the IVC, injection of corrosive substances into the hepatocaval network, biometry of the retrohepatic IVC and serial sections of injected livers. A total HVE should exclude the right suprarenal and phrenic veins. Clamping of the suprahepatic IVC depends on the termination of the left inferior phrenic vein. Clamping of the subhepatic IVC must be retrohepatic: the right lobe of the liver has to be mobilized to free the right border of the retrohepatic IVC into which flows the right suprarenal vein $40 \pm 20 \mathrm{~mm}$ above the right renal vein and under the superior right hepatic vein. Both suprahepatic and retrohepatic clamps excluding the retrohepatic portion of the IVC $(46.6 \pm 13 \mathrm{~mm})$ and the hepatocaval junction should come in contact behind the IVC without overlapping (Authors' summary).

Infographisme et enseignement médical. Enseignement assisté par ordinateur. Application à l'enseignement de l'os sphénoïde en anatomie (Graphics and medical teaching. Computer-assisted teaching. Its application to teaching the anatomy of the sphenoid bone) B Constantin, C Vanneuville, R Vasquez, S Riesco, J Juanes-Mendes (1989) Bull Assoc Anat 73: 15-17
Experience in teaching anatomy assisted by a computer is reported. By benefiting from collaboration with an information laboratory, it is possible at each stage of teaching to make, within the discipline, teaching discs for the students, together with a system of selfevaluation, thus avoiding numerous wearisome repetitions (Authors' summary).

Les pygomélies. Monstres unitaires ou monstres doubles ? (The pygomelus: a single or double monster?)

A Morin, JH Neidhardt, Th Basset, J Berard, CD Chapelon (1990) Bull Assose Anat $74: 43-50$

With an anatomical and a clinical case, the very rare monstrer, the pygomelus is described. Legend and reality have often been mixed in the literature. The condition cannot be definitely classified as either a single or a double monster (Authors' summary).

Etude de la vascularisation de la vésicule biliaire chez l'homme (Further observations on the vascular system of the gallbladder in man) MB Polyzonis, P Tsikaras, P Hytiroglou, A Agios (1989) Bull Assoc Anat $73: 25-28$

The authors present an experimental study of the vascularization of the gallbiadder, which was conducted by means of corrosion casting technique. Casts of the vessels of all calibers of 20 gallbladders were prepared. Our observations concern the morphology of the arteries and the veins of the gallbladaer, the architecture of the fine vessels of the microcirculation, the vascular communications between the gallbladder and the proximal part of the liver and, also, the vessels of the latter (Authors' summary). 